\title{
Erratum to: New insights into the roles of the N-terminal region of the $\mathrm{ABCC} 6$ transporter
}

\author{
Rocchina Miglionico $^{1} \cdot$ Andrea Gerbino $^{2}$ - Angela Ostuni ${ }^{1}$. \\ Maria Francesca Armentano ${ }^{1}$. Magnus Monné ${ }^{1}$. Monica Carmosino ${ }^{1}$. \\ Faustino Bisaccia ${ }^{1}$
}

Published online: 11 April 2016

(C) Springer Science+Business Media New York 2016

Erratum to: J Bioenerg Biomembr (2016)

DOI 10.1007/s10863-016-9654-Z

The figure for "Homology model of the conserved ABCC6 L0 domain" was inadvertently omitted from ESM 1. Further, on page 8, the reference to this figure is given as Fig. 4A which is incorrect and should refer to ESM 1. The correct ESM file and the citation has been updated in the original article. We regret the errors.

The online version of the original article can be found at http://dx.doi.org/ 10.1007/s10863-016-9654-z.

\footnotetext{
Monica Carmosino monica.carmosino@unibas.it

$\triangle$ Faustino Bisaccia faustino.bisaccia@unibas.it

1 Department of Sciences, University of Basilicata, 85100 Potenza, Italy

2 Department of Biosciences, Biotechnology and Biopharmaceutics, University of Bari, Bari, Italy
} 